\title{
Percent Predicted Forced Inspiratory Volume in 1 Second
}

National Cancer Institute

\section{Source}

National Cancer Institute. Percent Predicted Forced Inspiratory Volume in 1 Second. NCI

Thesaurus. Code C112380.

The volume of air that a subject can breathe in during the first second of inhalation after maximum exhalation as a proportion of the predicted normal value. (CDISC) 